\title{
EXPERIMENTAL LEARNING IN LEADERSHIP EDUCATION
}

\author{
Magdalena Kalińska
}

\author{
aDepartment of General Management, Faculty of Economic Sciences and \\ Management, Nicolaus Copernicus University, Toruń, Poland, \\ e-mail: kalinska@econ.umk.pl
}

\begin{abstract}
The paper will discuss experimental teaching methods for the development of leadership skills and propose methods of enhancing deep and reflective discussion. Everyone involved in leadership skills development classes, the lecturer, trainer or mentor, knows that if this process is ever to have greater effect, it must become much more experimental and reflective and much less didactic. Being a good leader requires both technical and personal competence. The question is how to create opportunities for students to find their leadership potential and to build a career in leadership, as well as how to help them reflect and grow as managers for the very first time.

Many students choosing this course wish to be great charismatic leaders. They are fascinated by examples of great world-class leaders and their innate talent, believing that they can too change organizations and motivate people easily. They talk about such people and their brave achievements. Some students are surprised by the content of the course mostly focused on developing interpersonal communication skills and to foster personal growth - in the sense of values, talents, personal way of learning and working, emotional intelligence problems, social intelligence problems and selfperception. There are many ways to explain to students the need for personal development. One is the use of role-playing games - to experience realistic situations, problems and challenges which the leader may face.

The outlined program encounters some problems. The role of the teacher is to create and carry out a variety of activities which are intended to have a positive effect on learners and to create an appropriate atmosphere for open discussion, comment and students' reflections. It is very important not only to discuss what happened during the lecture but also to encourage students to think about their personal characteristics and values after the classes. Some cultural aspects are also of great importance. The Internet forum where students can easily change their ideas is a very useful tool to solve those problems.
\end{abstract}

Keywords: leadership education, experimental learning, developing leadership skills, personal development

Paper type: Literature review

\section{Introduction}

For centuries we have been obsessed with leaders, and with identifying the characteristics required for effective leadership. Among a vast array of research many have pointed out that we still seem to know little about the defining characteristics of effective leadership. However, such observations do not appear 
EXPERIMENTAL LEARNING

Magdalena Kalińska to have stemmed our appetite for continuing the search. More importantly there is a lack of common sense about developing the subject during business studies. If we are not sure what makes a leader, how can we develop this in business education? What should a strategy for developing leadership capabilities look like? This paper is an attempt to answer this question.

\section{From the Weberian perspective to transformational leadership}

Exploring the drivers of interest in leadership some suggest that it reflects a basic human need to be led (Collingwood, 2001 a,b). Indeed, Freud (1927) maintained that groups of individuals need leaders to provide them with identity and a sense of purpose. There are a number of critical issues facing today's organizations (globalisation, changes in social values, changes in investors focus, challenges in implementing organizational changes, awareness of the impact of stress on employees, to name the few) which have leadership implications. These imply developing particular leadership competence to enable organizations to meet the challenges outlined above.

It is not within the scope of this paper to explore the concept of leadership in detail. However, it is necessary to mention trends and developments that influenced thinking about leadership and the leadership training.

A brief overview of the leadership literature gives the impression that until the late twentieth century, the paradigm was determined by the rational/ analytical perspective of Weber (1964). This led to the emergence of 'Taylorism' and 'Fordism', which was the dominant thinking on business organization and leadership. (Goffee and Jones, 2000; Higgs and Rowland, 2001). The impact of the 'modern' school, influenced by Freud, Jung, Skinner, etc., provides the second minor leadership discourse in the latter part of the twentieth century (Collingwood, 2001).

The 'modern' study of leadership began with Trait theory in the late 1920s. This was a personality-based approach and one which led to generally inconclusive findings (Fidler, 1964). The limitations of the Trait theory were responded to by examining the behaviour and style of leaders. This approach was underpinned by the idea that there was a 'best' style (Alimo-Metcalfe, 1995).

In another 'modern' study of leadership, namely 'charismatic theory', the focus of research was on the qualities of the 'heroic CEO'. This approach failed to produced compelling results and was very USA focused (Khurana, 2002).

In the late 1970s, the state of leadership research was such that methodological and terminological debates were causing more confusion than enlightenment. The rational paradigm derived from a Weberian perspective was in conflict with the psychological paradigm. A debate arose around the difference between leadership and management (Kotter, 1990). Possibly, influenced by this train of thought, Bass (1985) developed a leadership model which identified different 
behaviour characteristics required in situations of organisational transformation and situation of stability. Bass (1985) labelled these as transformational and transactional leadership.

Transformational leadership, has become a very popular concept in recent years. Bass (1990b) specified that transformational leadership: 'occurs when leaders broaden and elevate the interests of their employees, when they generate awareness and acceptance of the purpose and mission of the group, and when they stir their employees to look beyond their own self-interest for the good of group' (p. 21). Bass (1990a) stipulates that this transcending beyond self-interest is for the 'group, organization or society' (p. 53). In essence, transformational leadership is a process of building commitment to organizational objectives and then empowering followers to accomplish those objectives (Yukl, 1998).

Following through historical perspectives on leadership it is safe to assume that leadership involves both - personality and behaviour and so leadership education needs to put both qualities into the study curriculum. At the same time, in designing a leadership skills development lecture, the transformational leadership perspective could be extremely helpful. This is why the concept will presented in more detail.

\section{Transformational leadership and its possible roots}

Transformational leadership is concerned with progress and development. The leaders transform the personal values of followers to support the vision and goals of the organization by fostering an environment where relationships can be formed and by establishing a climate of trust in which visions can be shared. (Bass, 1985a). Avolio et. al. (1991) established four primary behaviours that constitute transformational leadership:

- Idealized influence

- Inspirational motivation

- Intellectual stimulation

- Individualized consideration

Idealized influence reflects behaviour that leaders enact because they choose to do what is right, rather than what is expedient, simple, or cost-effective. Leaders are guided to engage in this behaviour because of their moral commitment to both their own actions and to their followers (Turner, Barling, Epitropaki, Buchter and Milner 2002). Employees respect leaders who engage in behaviour that reflects idealized influence because they know that their leaders have chosen to behave in this way; they are not behaving this way just because they have to. Employees who see their leaders as doing right the thing are likely to trust and respect them and to have positive perceptions of interpersonal justice (Turner, Barling, and Zacharatos 2002). 
EXPERIMENTAL LEARNING

Magdalena Kalińska

Leaders evidence inspirational motivation when they inspire their followers to be their very best and to greater levels than the followers themselves ever thought possible. Unlike many popular, and perhaps populist notions of inspiration, inspirational motivation does not require the leader to display stereotypical charismatic behaviour. Instead, inspirational motivation within a transformational leadership context is achieved by convincing employees that they can break through previously perceived performance barriers, whether self- or externally imposed. Leaders do so by instilling in their employees realistic feelings of selfefficacy, feelings of what can be accomplished rather than fears of what cannot be accomplished. They frequently use symbols and stories to convey positive message.

Using intellectual stimulation, leaders no longer provide all the answers. They challenge their employees to think more for themselves and to continuously question their long-held and cherished assumptions.

Finally, individualized consideration is reflected through that behaviour in which leaders show their concern for their employees' development and physical and psychological well-being. They do this by listening, caring and empathizing, especially during the most difficult times when employees need them most. It is through individualized consideration that leaders develop and cement a relationship with their followers.

Given the usefulness of transformational leadership, attention should be tuned to other issues such as how it develops and what factors may predispose individuals to use transformational leadership (Rost, 1991). One of them is emotional intelligence (Sosik and Megerian, 1990, Barling at al., 2000).

In the present paper I use the classification initially enunciated by Salovey and Mayer (1990) and Goleman (1995). Thus, emotional intelligence comprises five characteristics, namely:

- Understanding (read) one's emotions;

- Knowing how to manage them (regulate);

- Emotional self-control, which includes the ability to delay gratification;

- Understanding others emotions, or empathy; and

- Managing relationships.

Goleman, (1998a, 1998b) argues strongly that emotional intelligence is a prerequisite for successful leadership, and it may be asserted that there are several reasons why individuals who are high in emotional intelligence would be more likely to use transformational behaviour.

First, leaders who know and can manage their own emotions, and who display self-control and delay of gratification, could serve as a role model for their followers, thereby enhancing their trust in and respect. This would be consistent with the essence of idealized influence. Second, with its emphasis on understanding others' emotions, leaders high in emotional intelligence would 
be ideally placed to realize the extent to which followers' expectations could be raised, a hallmark of inspirational motivation. Third, a major component of individualized consideration is the ability to understand followers' needs and interact accordingly. With its emphasis on empathy and the ability to manage relationships positively, leaders manifesting emotional intelligence would be likely to manifest individualized consideration.

Relationships between greater emotional intelligence and effective leadership could be driven by the conceptual overlap between the four aspects of transformational leadership behaviour relying heavily on the leader's personal, emotional and social skills (Bass and Avolio, 1994) and the personal, social and emotional abilities that make up emotional intelligence. Given the usefulness of transformational leadership and emotional intelligence, as lecturers, we can encourage students to develop suitable competence. The question is - how, and, is it too late to develop emotional intelligence?

Scientific inquiry strongly suggests that there is a generic component to emotional intelligence but psychological and development research indicates that nurture plays a role as well. Emotional intelligence is born largely in the neurotransmitters of the brain's limbic system which governs feelings, impulses, and drives so it can also be viewed_as an innate talent. On the other hand, practice clearly demonstrates that emotional intelligence increases with age, which means it can be learned to some extent, at any stage in life.

Research indicates that the limbic system learns best through motivation, extended practice, and feedback. Conducting personal training during study is a good starting point for developing the emotional capabilities of those students who are not as naturally emotionally intelligent. Unless the danger is that they are never 'an emotional intelligence star', the possibility of being a good leader increases. And with maturity the training can increase its effects. The next question arises: How to focus the training to include the limbic system for enhancing emotional intelligence? It requires an individual approach. Exercises and experiments where students can practice their attitudes, feelings and behaviour, together with well facilitated discussion to enhance possibility of making reflections about what happened, can be extremely useful.

\section{Experimental and reflective learning}

Recently, there has been growing criticism that business education including the teaching of leadership skills, has lost its original strong connection between learning and doing (Mintzberg and Gosling, 2002, Pfeffer and Fong, 2002). Learning today is far more focused on concepts and tools than on behavioural skills and action taking. Students primarily learn how to think and talk smart, but not to act smart. The neglect of behavioural and implementation training can 
EXPERIMENTAL LEARNING

Magdalena Kalińska

result in students graduating with strong conceptual expertise but weak skills in applying it to achieve positive business results.

The leading business schools emphasise research and teaching, and most faculty members are selected for their content knowledge and research skills, not for their expertise in teaching management practice. Only a small minority of business school professors have actually worked as executives in business organizations or served as senior managers in their own academic organizations.

Of course, one might retort that graduates today don't need much training in leadership skills because they won't be in a leadership position for a number of years. Even early career managers, however, is supposed to understand other people feelings and to have a capability to self-control as well possess the skill to cooperate with others. It is unrealistic to assume that managers will suddenly acquire leadership capabilities when they are promoted to senior positions. More likely, they will need to demonstrate this ability in order to get promoted.

Knowledge-in action enhancing leadership skills cannot be learned simply through lectures and reading; instead, it requires a healthy dose of learningby-doing. When faced with novel problems, new behaviour is tried out and assessed, thought about and talked about. In fact, discussion in the course of the lecture helps students to reveal their own feeling about things and compare it with colleagues. What is more important is the reflecting about the behaviour discovered, emotions, interactions and their consequences after classes. Possibly, the most crucial learning process takes place between classes.

People adopt new approaches more quickly if they are encouraged to revise their ideas about how to do things through intense and direct examination of what they have been doing. This is what is meant by reflection.

Experiments done by trial-and-error behaviour help to develop tacit knowledge and spontaneous to one's behaviour. The key is whether any given experience contains potentially relevant material for learning.

There is a vast array of 'learning by doing' activities on the education and training market that one can find and apply to in the learning process. Role-plays, exercises, case studies - all them are designed to help students to practice new behaviour and to reflect on selected issues. Case studies help students to argue their various points of view about situations for which there are not supposed to be 'right answers'. Role-plays are used in training to see how participants react in certain situations before and after training sessions. They give participants practice in dealing with other people in any given scenario. Even when the participant does it wrong, they still learn.

Although there is a wide range of exercise categories which can be used to achieve the feedback required in a particular learning aim, the most helpful for developing leadership skills are those fostering collaboration, improving communication skills and exercises involving diversity to show participants how 
one's attitudes and values can differ. The purpose of the feedback is not the only factor that the facilitator is supposed to bear in mind while choosing the exercise. The group dynamics, the atmosphere and the time when exercise is delivered also play important role. The facilitator can use icebreakers, communication exercises, mid-course energisers to align the group and keep them moving but also selfmanagement exercises.

The two main purpose of using icebreakers are, firstly, to allow the participants to introduce themselves to each other, and secondly, to lead into the topic matter. The more comfortable participants feel with each other, the better the learning environment.

Communication exercises are designed to let the participants find out where certain communication skills may be improved. Those stimulating conflict or dilemmas are the most helpful in this context, as they provide a rich laboratory of individual and group emotions and interactions.

Mid-course energisers can be used when the group is losing interest or falling asleep. It can also get people back on line or to help them think about a new approach to a problem. This can reduce tensions that may have built up with individuals or the group. Self-management exercises are designed to get participants thinking about particular aspects of their own personal skills, selfpresentation, attitudes and ambitions.

Given the usefulness of experimental learning in leadership education, attention should be turned to other issues such as what overall structure and objectives of leadership skills development course should look like? Should it be multidisciplinary? Should it integrate with other courses? How much experimental learning and personal development should be included in the course?

\section{The Leadership Skills Development Module - Design}

The Leadership Skills Development Module is on the core curriculum of Organization and Management Study at the Faculty of Economic Sciences and Management at Nicolaus Copernicus University in Torun, Poland. It is also an optional course for undergraduate students. The concept of experimental learning and reflection is central to the module's design. The aim is to develop students' understanding of and capacity for leadership, emotional intelligence, interpersonal behaviour and interpersonal communication. Students who complete the module should have, inter alia:

- An understanding of the personality and behavioural aspects of leadership

- An ability to connect leadership issues derived from a management perspective with other perspectives (e.g. psychology, psychology of sport, psychoanalytical perspectives) 
EXPERIMENTAL LEARNING

Magdalena Kalińska
- Developed (or at least increased awareness of) interpersonal skills as: listening skills, empathy and the ability to apply these in daily life.

- A capacity to reflect on their inner talents, values, attitudes, perceptions to develop self-awareness, and the ability to understand ones own behaviour and emotions.

The content of the module is classified in the syllabus into five interrelated sections :

1. Perspectives on leadership ( 25 per cent)

2. Interpersonal communication skills (20 per cent)

3. Emotional intelligence (5 per cent)

4. Personal development (40 per cent)

5. Social intelligence (10 per cent)

Content weightings are specified in brackets. However, the sections are interrelated and the expectation is that they will be delivered and assessed in an integrated fashion.

The focus of the perspectives on leadership section of the syllabus is on current interest in leadership. The specified topics are:

The difference between management and leadership, trait theory of leadership, behavioural and situational theories of leadership, charismatic theories, transformational and transactional theories, leadership in literature, leadership from a psychoanalytical perspective, how can leaders learn from the experiences of sport champions

Although interpersonal communication skills are an integral part of all sections, it is necessary to put in order and examine the issue through a broad range of disciplines, including communication, social science and psychology. Specified topics included in the syllabus in this regard are:

nature of interpersonal contact, connections between verbal and nonverbal cues, person perception, role and function of listening skills, barriers of interpersonal communication

The numbers of research and cases are constantly to tell us a persuasive story about the link between a company's success and the emotional intelligence of its leaders. Although we can group personal capabilities which drive outstanding leadership performance into three categories: purely technical skills like business planning, cognitive abilities like analytical reasoning and competencies demonstrating emotional intelligence, emotional intelligence is pointed out as the sine qua non of leadership. As mentioned before, scientific inquiry strongly suggests that there is a generic component to emotional intelligence and nurture plays a role as well. On the other hand, research also demonstrates that people can, if they take the 
right approach, develop their emotional intelligence. So the specified topics in this section are:

connections between leadership and emotional intelligence; neurological roots of emotions; self-awareness, self-motivation, empathy, sensing the situation

The personal development section is the most reflective one. The aim is to help students, even if they think they are modestly endowed, to manage themselves - to find their strengths through feedback analysis, ways of performing, sense of their values. The specific topics included under personal development are:

feedback analysis, Howard Gardner on multiple intelligences, ways of learning, differences between talents, knowledge and skills, self-values, self-goals, selfbelieves, the notion of flow, attitudes to work

Social intelligence, as an individual ability to get along well with others and to get them to cooperate with individual, was initially discussed as a part of emotional intelligence but the importance of the subject for leadership put it into separate section. The specified topics are:

differences between social and emotional intelligence, situational awareness, authenticity, clarity, self-presence, social self-awareness

\section{The Leadership Skills Development Module - Delivery}

The course is delivered using a mixture of lectures, role-playing games, exercises and discussion over a 10 week period (three contact hours per week). Each section is divided into phases for delivery purposes. An average meeting include the following elements:

- discussion on theoretical issues and problems that underline particular section;

- discussion on theoretical issues and problems drawn from the best examples;

- exercises designed to help to analyse and develop one's personal skills, attitudes, interests and objectives;

- experimental learning activities which may be videoed for further discussion;

- group discussion about what happened, participants behaviour and feelings;

- group discussion about the participants' experiences;

- discussion using an internet forum designed specially for the purpose of the lecture. 
EXPERIMENTAL LEARNING

Magdalena Kalińska
The course starts with en exercise offering participants an opportunity to explore the leadership-followers connection: the conflicts associated with leadershipfollowers dynamics, communication barriers and the participants feelings. The discussion about what happened follows the game and is an icebreaker to present the idea that leadership means both: behaviour and skills. The leadership theory is delivered then. The best examples of leadership failures are discussed. Depending on the engagement of the participants, there could be a opportunity to move the discussion to an internet forum.

The internet forum plays a complementary role in the course. Designed particularly for the purpose of the lecture, it is supposed to encourage students' reflection between the lectures, pluck up the courage of ones who are not so brave to present their ideas and experiences in the class. The forum also enhances the possibility of stepping back and reflecting thoughtfully on events or 'happenings' which become experiences only when they are digested, related to general patterns, and synthesised.

When asked to continue discussion via the internet forum, students feel confused and tentative at first, so there is a need to obtain the commitment of a few of them to start the discussion. It is useful to spot the ideas which seemed to be the most controversial for the group and then continue the topic through the internet forum. Also, by asking for assistance with preparing the lectures and conducting the exercises, students feel jointly responsible for the discussion.

The main goal of the communication section is to give the students an idea how much of interpersonal communication is non-verbal. Generally that section is carried on through internet forum but a lot of exercises connected with common communication barriers, and scenario examples which vividly illustrate the process, are provided during the presentation of theoretical issues. The exercises mainly concern listening problems, and as I often point out, listening is the skill that separates 'the great from the near-great'. The typical students feedback on listening problem is that they have never thought about listening as a communication barrier. When asking about critical analysis of their daily conversations they make revealing insights. The clues for that problems usually emerge during the discussion through the internet forum.

The emotional intelligence section is the most theoretical one but some psychological knowledge needs to be delivered to students to understand the concept. The lecture starts with the examples of situations presenting a lack of emotional intelligence and connected questions. The answers are supposed to emerge in the course of the lecture. But students are asked to make notes on the listed questions upon behaviour after classes. In particular, they are asked to observe their feelings connected with team work and situations when they loose their temper. The discussion of the findings takes place in the social intelligence section when differences between the two are emphasized. 
Talking about cross-cultural issues is very helpful at this stage. Being abroad can provide a good chance for learning empathy. It makes it clear and stresses the importance of observing and sensing other people's feelings through non-verbal behaviour. The discussion is led mainly via the internet forum. The aim of the discussion is to detect the differences between cultures. As many Polish students are used to studying abroad or taking summer jobs abroad they experience many different cultures - different perceptions and attitudes to social situations. Reflecting on the issue is a good starting point for looking for explanations of one's perception and attitudes and, then, for greater understanding.

The personal development section is the most reflective one. Some theory is presented but the exercises contribute most. Defining the strengths, as a mix of talents, knowledge and skills, is crucial for further discussion. A feedback analysis is suggested as a tool for revealing the strengths and areas for a prospective career. The aim is to find talents defined as a 'recurring pattern of though, feeling, or behaviour, that can be productively applied' (Buckingham, Coffman, 1990) and then to go to work on acquiring the skills and knowledge ones need to fully realize the strengths. At the same time, the feedback analysis is supposed to reveal bad habits or lack of manners. Practising the feedback analysis is anticipated for a long time -9 or 12 months, hence the exercises provided on the lectures seemed to be a good solution. A wide range of exercises is available on the educational market. The exercises I used in previous years were: finding one's work values, needs and drivers of motivation, looking for one's skills. A short discussion about students' findings also provides an opportunity to discern more clearly their own backgrounds in relation to their colleagues and the diversity of values and attitudes. I always suggest reconsidering and reflecting on one's behaviour and attitude in the students work-team condition, and among a group of colleagues, as a good prognosis of behaviour in the work environment.

In this part of the course two texts are strongly recommended to students: G. Corney and M. Corney's article about the sense of life and values (Stewart, 1995), and M. Csikszentmihalyi's text about work as a flow (Csikszentmihalyi, 1990). Both of them are quite controversial and discussion of them deepens differences in opinions within a group. The experience from previous years encourages the use of discussion based on these texts as an exercise on conflict management. The aim is to show students that things that they take for granted, such as their attitudes to work and values, may be totally different for others, that there could be many ways of life, ideas for career and though different, they do not exclude each other. At the same time, during the realisation of the exercise on conflict management, other problems arise: those connected with the culture of communication, the importance of language during discussion and understanding of other people's feelings. This exercise, well facilitated, could be crucial for the
EXPERIMENTAL LEARNING

Magdalena Kalińska 
EXPERIMENTAL LEARNING

Magdalena Kalińska next part of the course, especially, in creating a background for open discussion on other issues.

Having found about their attitudes, values and skills students can ask themselves about how other people see them. The social intelligence section is delivered twofold - by case study analysis of behaviour revealing lack of social skills and through interviewing colleagues from the group, outside the group, or family about the attitudes and values they see themselves as demonstrating. This is also a good time to test their instincts against reality.

The social intelligence issues always provoke discussion about self-presence and building an image attractive for others and still be authentic. The question is: how to attract followers while remaining true to oneself?

That part of the module is the most appealing for the students. They are willing to discuss strategies for increasing their social intelligence and attractiveness to others. Although the challenge facing all those who aspire to be leaders is to be themselves a training can help to find a way to express the strengths and use their difference for their benefits. Awareness off strengths and weaknesses can help individuals develop a unique style that works for them.

\section{Discussion and role-playing problems}

If the here-and-now experience is to provide a demanding environment where learning could be deeper, more consequential, and more enduring, it needs to be well mediated by a facilitator. It means that lecture style leads to many requirements and tasks for the teacher. In many particular situations, the problems taken on by the lecturer request for being a mentor, for active listening to the students, even to get inside their hearts to sense how to give effective feedback. Students are not supposed to be left with acquired knowledge. They have to transform tacit knowledge into implicit one. On the one hand, the discussion requires progress, the flow of discussion has to be somehow controlled, some theoretical background needs to be delivered. In contrast, the facilitator's role is not so important here. As was mentioned before, the time and place of the lecture, the group dynamics, the atmosphere and some issues connected with the cultural context of the group should also be borne in mind when planning the course.

To sort out the thoughts and practices about teaching leadership, the transformational leadership perspective is extremely helpful. Given the usefulness of transformational leadership, the same clues the teacher can use to engage and motivate students for making progress and reflections in leadership skills development. The four behaviours that make up transformational leadership: idealized influence, inspirational motivation, intellectual stimulation and individualized consideration can as much help students to develop their leadership skills, as to transform the personal values of followers in business to support the vision and goals of the organization. It works, firstly, by fostering an environment 
where relationship can be formed and, secondly, by establishing a climate of trust which makes learning efficient.

Idealized influence suggests the importance of style and personality of the teacher. Being a teacher/facilitator/mentor requires absolute engagement and continuous development of teaching methods. But, as was mentioned, in the case of the leader, the technical skills are 'threshold capabilities' and the emotional intelligence plays the main role in the lecturing process as well.

Inspirational motivation could advocate for inspiring the students to be their very best and to greater levels than the students themselves ever thought possible. In many cases it just could mean to show the students that there is a vast number of areas in which they posses talents or help them to find talents. Study time is the perfect time for such searching but it requires discussion about self- or externally imposed barriers, breaking deep-rooted beliefs about themselves. The teacher can encourage students to engage in realistic self-assessment, motivate them to set realistic but, skill-challenging goals. A suitable selection of readings and cases can be persuasive in showing the benefits of engaging in activity just for the pleasure of accomplishment the goals, instead external factors as salary or status. What is important, using intellectual stimulation, teacher no longer provide all the answers for students. Rather challenge students to think more for themselves and to continuously question their cherished assumption.

Finally, individualized consideration calls for deep concern for the students' development and physical and psychological safety. Teacher can accomplish it by active listening, caring, and being emphatic. The act of making questions, listening and reacting on students response is crucial for the discussion process.

Learning through discussion requires developing freedom and open atmosphere in the course of the lecture. This enhances students' commitment and participation in the lecture. Discussion is a very dynamic process. To have a greater effect it is impossible to conduct the discussion firmly, to control everything what is happening during the lecture.

The atmosphere at the lecture and the level of discussion vary also according to the group of students. Sometimes it can be a vivid living adventure, at another time students stay stiff and reserved presenting their point of view. In the first example writing short notes and clue words down on the board is very helpful. Leaving 10 minutes at the finish of the lecture for students purpose, to write report on what happened during the lecture is also very recommendable. My personal custom is also to move discussion to the internet forum. In the second case, when students stay reserved, I use the mid-course energiser games to find their interests, to wake them up or to reduce tensions that may have built up with individuals or the group.

For the process of discussion, the attitude of students towards the teacher and the lecture is crucial. As the module is designed for students who have leadership 
EXPERIMENTAL LEARNING

Magdalena Kalińska ambitions or students can chose the course as an optional module, their attitude to lectures is very meaningful. In fact, a much deeper problem can arise, a problem deriving from the Polish national culture, namely, the high power distance between students and their teacher. It may appear for two reasons. Firstly, Polish students are rather used to listening to the lecture without active participation, so they feel confused when they are invited to participate in a discussion. Secondly, students keep feeling uncomfortable when questioning teachers' statement or asking question to the teacher. My experience is that the first lectures are of key importance to create the atmosphere of an open discussion and encourage the freedom of opinions. I try to utilize the so-called 'potential of good start' in many ways. Firsly, I start with the icebreakers. Secondly, by being close to my students, by asking questions before the start of the lecture, discussing their current commitments to other lectures. Active listening to the answers still remains a good icebreaker as well. Also, I use an idea taken from practical leadership experience, which states that one of the golden rules of leadership is to reveal one's weaknesses (Goffee and Jones, 2000). Such admission is supposed to reveal humanity and sent out an implicit message: 'I am like you - imperfect'. One of the benefits coming from revealing weaknesses is that you show how others can help you which builds good teamwork. In my case it usually means getting students engaged in helping one another and cooperation over arranging the exercises, or preparing questions for the lecture based on the set text.

\section{Conclusion}

My objective in this article is to provide a perspective on the practice in teaching leadership. I realize that the proposed programme, which works well for me may not work well for others. But I believe that most leadership teachers, mentors or trainers, will agree that leadership should be taught and may be taught at any age. The key issue is how to structure and teach this important subject.

During the designing of the curriculum I have made some basic assumptions. The first is that transformational leadership could be a convincing idea to structure the skills and behaviour that make up leadership. The second is that specific transformational leadership competencies are based on emotional intelligence. Moreover, I assume that the same attitudes I propose to students as a 'the basis for leadership' could be applied too, and motivate them for making progress and reflections about their lives, values, and behaviours. But reflection alone is not enough, experimental learning for leadership plays a vital role as well.

Different emotional reaction patterns, or any social pattern of behaviour - if it is a negative pattern, which were probably learned in childhood - can be broken. It just needs to be replaced with a positive response. This process takes a lot of work, commitment, and motivation on the part of both the teacher and the learner. Certainly, it could not be done during a single study module. But a teacher can 
give students a specific goal and structure for learning. They must know what they are trying to accomplish, and they must practice it not just during lectures but during their whole lives.

I have focused on how to help students to get insights and find their strengths for being leaders over the course of the last 10 years. This is the very start of my research work about leadership and of obtaining the feedback. It needs time for my students to be promoted to leadership positions and start to apply their leadership skills. At this stage I gather information on the basis of interviewing the students, keeping in contact with them. The results seem to be promising. Students observe some changes in their behaviour and try to develop and practice them.

It is still necessary to build on the development by drawing on the experience of the module delivery and developing, and possibly amending and/or extending, the approach. 'Be realistic and never stop learning' - I still bear in mind the message I send to students and I keep following it.

\section{References}

Alimo-Metcalfe, B. (1995). "An investigation of female and male constructs of leadership and empowerment". Women in Management Review. Vol. 10 No 2. pp. 3-8.

Avolio, B. Waldman, D. and Yammarino, F. (1991). "Leading in the 1990s: the four Is transformational leadership". Journal of European Industrial Training. Vol. 15 No 4. pp. 9-16.

Bass, B.M. (1985a). Leadership and Performance Beyond Expectations. Free Press. New York. NY.

Bass, B.M. (1985b). "Leadership: good, better, best". Organizational Dynamics. Vol. 13 No. 3. pp. 26-40.

Bass, B.M. (1990a). Bass and Stogdill's Handbook of Leadership: Theory, Research, and Managerial Applications. $3^{\text {rd }}$ ed. The Tree press. New York. NY.

Bass, B.M. (1990b). "From transactional to transformational leadership: learning to share the vision". Organizational Dynamics. Vol. 18 No. 3. pp. 19-31.

Buckingham, M. and Coffman, C. (1990). First, Break All the Rules: What the World's Greatest Managers Do Differently. Simon \& Schuster.

Collingwood, H. (2001a). "Leadership's first commandment: know thyself". Harvard Business Review. December. p. 8.

Collingwood, H. (2001b). "Personal histories". Harvard Business Review. December, pp. 27-38.

Csikszentmihalyi, M. (1990). Flow: The Psychology of Optimal Experience. Harper \& Raw Publishers, Inc.

Drucker, P. F. (1999). „Managing Oneself”, Harvard Business Review. Marc-April. pp. $64-74$

Fiedler, F. (1964). "A contingency model of leadership effectiveness". in Berkowicz, L. (Ed). Advances in Experimental and Social Psychology. Academic Press. New York. NY.

Freud, S. (1927). Civilizations and Its Discontents. Hogarth Press. London.
EXPERIMENTAL LEARNING

Magdalena Kalińska 
EXPERIMENTAL

LEARNING

Magdalena Kalińska
Gardner, H. (1993). Frames of mind: The Theory of Multiple Intelligences $\left(10^{\text {th }}\right.$ anniversary edition). New York: Basic Books.

Goffee, R. and Jones, G. (2000). "Why should anyone be led by you?". Harvard Business Review. September- October. pp. 63-70.

Goffee, R. and Jones, G. (2005). "Managing authenticity. The paradox of great leadership". Harvard Business Review. December. pp. 87-94.

Goleman, D. (1995). Emotional intelligence. Bantam Books. New York. NY.

Goleman, D. (1998). "What makes a leader?". Harvard Business Review. November - December. pp. 93-102.

Higgs, M.J. and Rowland, D. (2000), "Building change leadership capability: The quest for change competence". Journal of Change Management. Vol. 1 No. 2, pp. 116-31.

Kaagan S.S. (1990), Leadership games. Experimental Learning for Organizational Development, Sage Publications, Inc.

Khurana, R. (2002) "The curse of the superstar CEO", Harvard Business Review. September. pp. 60- 66.

Kotter, J. P. (1990) „What leaders really do“, Harvard Business Review. May- June. pp. $37-60$.

Kroehnert, G. (1991) 100 training games. McGraw-Hill Book Company Sydney.

Mintzberg, H. and Gosling, J. (2002) "Reality programming for MBAs". Strategy and Business. 26 (1). pp. 28-31.

Pfeffer, J. and Fong, C. (2002) "The end of business schools? Less success than meets the eye". Academy of Management learning and Education. Vol. 1. pp. 78-95.

Salovey, P. and Meyer, J.D. (1990) "Emotional intelligence". Imagination. Cognition and Personality. Vol 9. pp. 185-211.

Sosik, J.J. and Megerian, L.F. (1990) "Understanding leader emotional intelligence and performance: the role of self-other agreement on transformational leadership perceptions". Group and Organizational Management. Vol. 24. pp. 367-90.

Stewart, J., (1995). Bridges Not Walls: A Book about Interpersonal Communication. McGraw-Hill. Inc.

Turner, N., Barling, J. and Zacharatos, A. (2002). "Positive psychology at work", in C.R. Snyder \& S.J. Lopez (Eds.), Handbook of positive psychology, New York: Oxford University Press., pp. 715-728.

Turner, N., Barling, J., Epitropaki, O., Buchter, V. and Milner, C. (2002). „Transformational leadership and moral reasoning“. Journal of Applied Psychology. Vol 87. pp. 304-11.

Yukl, G. 1998. Leadership in Organizations, 4rd ed.. Prentice-Hall. Inc. Upper Saddle River. NJ. 